\title{
EDITORIAL
}

\section{O Futuro da Revista Cientifica do Hospital Santa Izabel}

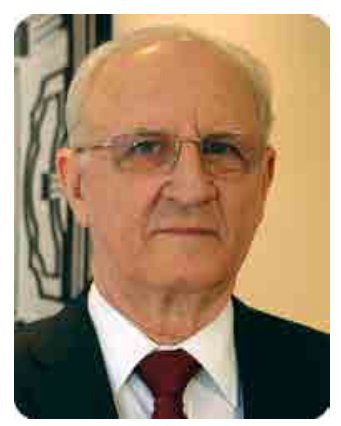

\section{The Future of the Hospital Santa Izabel Scientific Journal}

\author{
Gilson Soares Feitosa ${ }^{*}$ \\ ${ }^{1}$ Diretor de Ensino e Pesquisa do Hospital Santa Izabel, Editor-Chefe da Revista \\ Cientifica Hospital Santa Izabel; Salvador, Bahia, Brasil
}

Já cumpridos alguns anos desde o seu lançamento, a Revista Científica do Hospital Santa Isabel (RCHSI) pode deitar um olhar complacente sobre sua realização.

Atentando-nos para os princípios que norteavam o seu lançamento em março de 2014, à época sob o nome de Revista de Saúde do Hospital Santa Isabel, apenas mudando para Revista Científica do Hospital Santa Isabel em 2017, pode confirmar-se que os seus propósitos foram cumpridos, ou seja: motivar a nossa massa crítica de profissionais de saúde altamente qualificada a documentar sua experiência sob a forma de artigos de atualização, relatos de caso, discussão de protocolos da prática médico-assistencial e divulgar os resumos de artigos publicados por nossos colaboradores em revistas indexadas. O espirito colaborativo dos médicos e profissionais de saúde do HSI, além da sua esmerada e crescente qualificação foram sobejamente constatados.

A hipótese levantada de que havia condições para fazê-lo se confirmou com a absoluta regularidade de números publicados trimestralmente, sendo apenas constatada uma única exceção, quando nos meses de setembro e dezembro de 2020 foram reunidos em um só número, por conta da pandemia da COVID-19.

Essa regularidade das publicações tem sido um dos pontos de destaque da revista.

Com o apoio, sempre oportuno e bem-vindo, da provedoria, chega o momento em que devemos avançar a nossa qualificação enquanto revista científica de saúde.

Já conquistamos há anos o ISSN para a revista. Há pouco tempo

Correspondence addresses: Dr. Gilson Soares Feitosa gilson-feitosa@uol.com.br

Copyright

(C) 2021 by Santa Casa de Misericórdia da Bahia. All rights reserved. ISSN: 2526-5563

DOI: 10.35753 conseguimos o Digital Object Identifier (DOI)e CrossRef, sua indexação no Google Acadêmico, Latindex e Ex Libris Ulrich's Database (uma das bases de dados mais antiga do mundo), e, agora, procuraremos registrá-la em vários outros repositórios de indexação, nacional e internacional.

Vamos expandir o seu corpo do conselho editorial que embora ainda se fundamente nos que compõem o corpo de professores do programa de residência médica e multiprofissional do Hospital Santa Isabel, será extensivo a outros profissionais do hospital e fora dele. 
Manteremos a prática do convite para atualização, porém vamos abrir decididamente a oportunidade de publicações de trabalhos originais de várias instituições envolvidas com a produção científica.

Esses trabalhos originais serão publicados em inglês de modo a garantir o seu desejado alcance internacional.

Nunca nos deitaremos no terreno das conquistas feitas, senão que sempre procuraremos avançar com bons propósitos! 